\title{
INTERNET CONVENIENCES, CHALLENGES, AND RESEARCH ETHICS FROM NOVICE RESEARCHER PERSPECTIVE
}

\author{
Saepudin Nirwan \\ Politeknik Pos Indonesia, nirwansaepudin@poltekpos.ac.id
}

\section{Background}

Currently, the internet provides convenience, where the internet provides various resources needed by a researcher, from collecting references in the form of journals, data, and tools for managing research. The benefits offered by the internet through the provision of various references, data, and search tools and managers, for example, the most popular among new researchers is google search engine database with the alert mechanism (Creswell, 2005). Behind the ease in the study received a variety of sources, a novice researcher to confront the ethics of cited and explore ideas from various sources.

In this study, the author will present an opinion on several matters related to the following questions:

1. What are the challenges facing research ethics a novice researcher with the convenience of the internet?

2. How is a novice researcher to face this challenge?

3. What is support it takes a novice research to guide undertaking research ethics? From some of the above questions, the author tried to describe it as follows.

\section{Convenience of Internet being Challenges Faced in Research Ethics of a Novice Researcher}

The ease of getting a variety of research resources are provided the internet can spur the spirit of novice researchers to conduct discovery of knowledge, but if not careful, 
the information obtained becomes overloaded so that the possibility of achieving research goals becomes blurred. For example, because of the large literature that has been read can create a novice research becomes uncertain and difficult to define the research problem. Required a road map to determine the problem research supporting the novice researchers (Ellis, Levy, \& Lauderdale, 2008). The intelligence of novice researcher to do analysis and literature review is necessary to deal such issues, a novice researcher should have a good basic ability of the literature review and analytical abilities of the research interest. To address the abundance of resources available, novice researcher must also have the ability to manage resources such research, how to sort, store and manage citations from journals, proceedings, books, the web and other resources with tools that are also based on ICT (Information and Communication Technology) and the internet.

\section{How is a Novice Researcher to face this Challenge?}

A novice researcher is expected to have the ability to adapt to the environment and the researchers who are in the area of research interest. As a social responsibility, novice researchers required becoming members of the research community where the study area is located, through various social media (Facebook, tweeter, linked, forums) and ICT research tools (for example, Mendeley, EndNote, etc.). With communication and being part of a community of researchers, a novice researcher has the opportunity to communicate and know the position of research currently lived (S. Ali, 2016).

By knowing the areas of research and the research community that become an interest, a novice researcher will get to know the major sources in the area of research, communication, and discussion with senior researchers as the reference in the field of research, attending conferences, publishes papers, as well as creating a network (Indiana.edu, 2016). Thus fraud and misconduct such research; not to publish the study 
as a whole, the duplication of research, or report the results selectively, (Elia, von Elm, Chatagner, popping, \& Tramèr, 2016) can be avoided.

\section{What is Support It Takes a Novice Researcher to Guide Undertaking Research Ethics?}

The main ability a novice researcher is adhering to the guidelines where researchers are involved, organization, government, and sponsor for specific research. The research institution in which a researcher shelter must establish strict policies and observe every step of the study conducted by researchers under his supervision, nurturing conducted by the institution be of key importance. The ability of a novice researchers in understanding the ethical guidelines in research by itself create a novice researcher to be careful at the same time flexible in running research. For example, a novice researcher not worry be plagiarism and misconduct other research, because it has a good knowledge of it.

As a novice researcher, the supervision of a senior researcher become a necessity that cannot be avoided, the guidance and direction of a supervisor can accelerate the growth of the capacity of independent research on novice researchers (P. A. Ali, Watson, \& Dhingra, 2016). Three major factors to support novice researchers to adapt and adopt the ethics of research in his career as a researcher, as shown in Figure 1 below. 


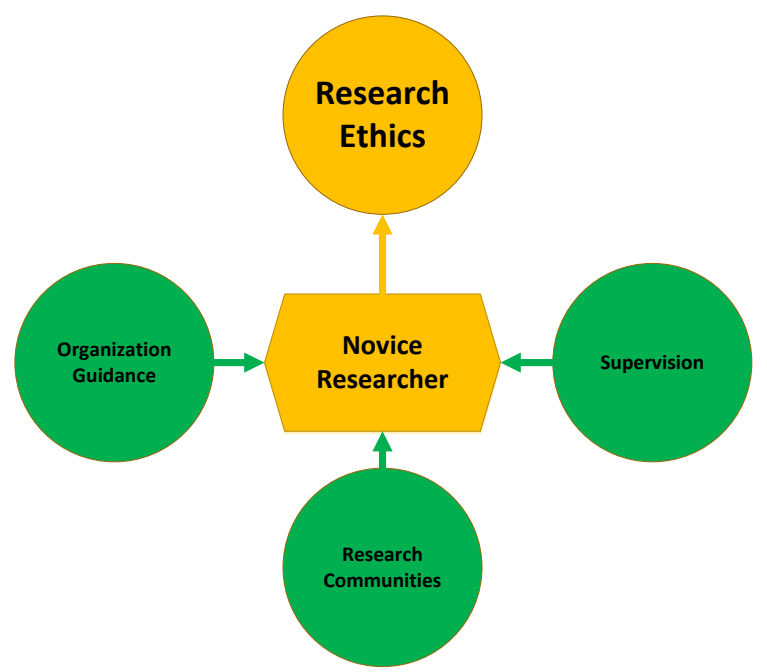

Figure 1: Shaping Novice Researcher to Research Ethics

Techniques and lessons learnt from a supervisor or a reputable organization could also help encourage novice researchers to replicate the ability of primary research in him, thus novice researchers have been ready to become qualified independent researchers and uphold the ethics of the research.

\section{Conclusion}

Research ethics to guide novice researchers in conducting research without fear of slipping into misconduct research. Understanding the ethics of research means a novice research has been ready to become independent professional researchers. The ability to use internet resources as well as a variety of tools that can help the process of research into the medium to search, acquire, communicate and be part of the research area in which researchers community located. According to the authors, there are three main supporting elements in the form of research ethics for a novice researcher; outstanding institution, the outstanding supervisor and the research community in which novice researchers are involved. 
References:

Ali, P. A., Watson, R., \& Dhingra, K. (2016). Postgraduate Research Students ' and their Supervisors' Attitudes towards Supervision, 11, 227-241.

Ali, S. (2016). ICT feasibilities for doing a better research, 16(10), 93-97.

Creswell, J. W. (2005). Educational Research: Planning, Conducting, and Evaluating Quantitative and Qualitative Research. Pearson (4th ed.). http://doi.org/10.1017/CBO9781107415324.004

Elia, N., von Elm, E., Chatagner, A., Pöpping, D. M., \& Tramèr, M. R. (2016). How do authors of systematic reviews deal with research malpractice and misconduct in original studies? A cross-sectional analysis of systematic reviews and survey of their authors. BMJ Open, 6(3), e010442. http://doi.org/10.1136/bmjopen2015-010442

Ellis, T. J., Levy, Y., \& Lauderdale, F. (2008). Framework of Problem - Based Research - A Guide for Novice Researchers on the Development of a Research Worthy Problem. The International Journal of an Emerging Transdiscipline, 11, 17-33. http://doi.org/DOI GOES HERE

Indiana.edu. (2016). http://www.cs.indiana.edu/how.2b/how.2b.community.html.

Retrieved December 4, 2016, from

http://www.cs.indiana.edu/how.2b/how.2b.community.html 